\title{
Reflexões sobre a decolonialidade em uma perspectiva histórica
}

\author{
Reflections on decoloniality in a historical perspective
}

\section{Antonio Guimaraes Brito}

Resumo: O colonialismo revelou ser a face oculta da Modernidade, inserido no processo histórico da dominação eurocêntrica. Contudo,a partir do pós-guerra, de uma forma mais evidente e contundente, inúmeras manifestações intelectuais surgiram no sentido anticolonial, em especial no continente africano, asiático e latino-americano. Nesse artigo,será primeiramente analisado o debate teórico anticolonialista, sobretudo com base na obra de Franzt Fanon e Albert Memmi como também o pós-colonialismo do intelectual palestino Edward Said. Posteriormente, buscar-se-á uma aproximação teórica do descolonialismo de Walter Mignolo, com a perspectiva descolonialista da Filosofia da Libertação de Enrique Dussel.

Palavras-chave:

Póscolonialismo;

Colonialidade.
Anticolonialismo; Descolonialidade;

Doutor pela Universidade Federal de Santa Catarina Prof. Associado Universidade Federal do Rio Grande tombrito@yahoo.com

Abstract: Colonialism proved to bethehidden face of Modernity, inserted in the historical process of Eurocentric domination. However, from the post-warperiod, in a more evident and force fulway, in numerableintellectualmanifestationsarose in theanti-colonialsense, especially in the African, Asian and Latin American continent. In thisarticle, wewillfirstanalyzetheanticolonialisttheoretical debate, mainly based on the work of Franzt Fanon and Albert Memmi as well as the post-colonialism of the Palestinian intellectual Edward Said. Subsequently, a theoretical approach to Walter Mignolo's decolonialism Will besought, with the decolonialist perspective of Enrique Dussel's Philosophy of Liberation.

Keywords:

Anti-colonialism; Postcolonialism; Decoloniality; Coloniality. 


\section{Anticolonialismo}

O anticolonialismo analisa o processo histórico da dominação eurocêntrica, enfatizando o caráter racista das políticas coloniais. Preocupa-se principalmente com a violência do colonizador e a desfiguração do colonizado, como também com os arranjos políticos do período de transição das forças colonizadoras e o surgimento de nações independentes. A crítica anticolonial assume também um caráter de denúncia da condição do colonizado.

Todavia, antes de tudo, a principal característica do anticolonialismo é o conceito fechado do colonialismo, ou seja, a ideia central do período histórico passado. Ou seja, temporal, compreendendo determinado período da história, quando existiam colônias no aspecto didático, até as emancipações das metrópoles. Os autores ligados ao anticolonialismo entendiam o processo da descolonização como sinal do período colonial histórico. Diferentemente do conceito de colonialismo, a ideia de colonialidade foi posteriormente assumida pelos teóricos decolonialistas latino-americanos. Como observa Quijano (2007: 93), o colonialismo se refere a um padrão de dominação e exploração no qual:

O controle da autoridade política, dos recursos de produção e do trabalho de uma população determinada possui uma diferente identidade e as suas sedes centrais estão, além disso, em outra jurisdição territorial. Porém nem sempre, nem necessariamente, implica relações racistas de poder. O colonialismo é, obviamente, mais antigo; no entanto a colonialidade provou ser, nos últimos 500 anos, mais profunda e duradoura que o colonialismo. Porém, sem dúvida, foi forjada dentro deste, e mais ainda, sem ele não teria podido ser imposta a intersubjetividade de modo tão enraizado e prolongado.

Nessa mesma direção, Maldonado-Torres (2007: 131) esclarece a distinção entre os dois conceitos, colonialismo e colonialidade:

O colonialismo denota uma relação política e econômica, na qual a soberania de um povo está no poder de outro povo ou nação, o que constitui a referida nação em um império. Diferente desta ideia, a colonialidade se refere a um padrão de poder que emergiu como resultado do colonialismo moderno, mas em vez de estar limitado a uma relação formal de poder entre dois povos ou nações, se relaciona à forma como o trabalho, o conhecimento, a autoridade 
e as relações intersubjetivas se articulam entre si através do mercado capitalista mundial e da ideia de raça. Assim, apesar do colonialismo preceder a colonialidade, a colonialidade sobrevive ao colonialismo. Ela é, mantém viva em textos didáticos, nos critérios para o bom trabalho acadêmico, na cultura, no sentido comum, na auto-imagem dos povos, nas aspirações dos sujeitos e em muitos outros aspectos de nossa experiência moderna. Nesse sentido, respiramos a colonialidade na modernidade cotidianamente.

Ou seja, a colonialidade sobrevive ao fim do colonialismo e da emancipação das colônias latino-americanas, asiáticas e africanas, dando um conceito mais amplo e complexo ao processo da descolonização.

Nesse contexto, por volta da década de 1960 e 1970, destacam-se os autores antilhanos Aime Césaire e Frantz Fanon, como também o tunisiano Albert Memmi. Franzt Fanon, nascido em 1920 na Martinica, tornou-se médico psiquiatra do Exército francês, no hospital de Blida, na Argélia. Dessa forma, tornou-se testemunha ocular do sofrimento e das mazelas da guerra colonial. Sua obra "Os condenados da terra" trata-se não apenas de uma reflexão crítica sobre o colonialismo, mas de um depoimento de sua experiência com a crise do colonialismo francês no Norte da África. Publicada em 1961, e prefaciada por Jean Paul Sartre, essa obra é uma análise do autor sobre a extrema violência colonial. Como aponta Fanon (1968: 32): "A violência com que se afirmou a supremacia dos valores brancos, a agressividade que impregnou o confronto vitorioso desses valores com os modos de vida ou de pensamento dos colonizados fazem com que, por uma justa reviravolta das coisas, o colonizado ria com escárnio ante a evocação de tais valores".

Essa violência colonial provoca um processo radical de barbarização do outro, ou seja, a total desumanização do colonizado. Ainda nessa direção, enfatiza Fanon (1968: 30) que "O mundo colonial é um mundo maniqueísta", mas esse maniqueísmo significa antes de tudo anegação total da humanidade da vítima do colonialismo". Como pondera o autor (1968: 31), "Por vezes este maniqueísmo vai até o fim de sua lógica e desumaniza o colonizado. A rigor, animaliza-o. E, de fato, a linguagem do colono, quando fala do colonizado, é uma linguagem zoológica”. Fanon analisa os fatores políticos, sociais, culturais e econômicos do processo colonial e descolonial, e revela a dramaticidade da violência física, moral e principalmente simbólica. Para o colonizado, segundo Fanon (1968: 73), “[...] a vida só pode surgir do cadáver em 
decomposição do colono”, pois a “[...] a descolonização é simplesmente a substituição de uma 'espécie' de homens por outra 'espécie' de homens" (FANON, 1968: 25); ou seja, a passagem do bárbaro não-humano, como não ser, para o reconhecimento de sua singularidade humana. Para descolonizar, é necessário primeiro conhecer a extensão do colonialismo, pois, conforme aponta Fanon (1968: 27), "Há portanto na descolonização a exigência de um reexame integral da situação colonial". Inclusive quanto ao processo interno de colonização das elites nativas, cooptadas pelo imaginário colonial. Da mesma forma, Albert Memmi, ensaísta tunisiano, ao publicar sua obra "Retrato do colonizado precedido pelo retrato do colonizador", dividida em duas partes, desenha primeiro o retrato do colonizador, superior, justificado, e depois a imagem do colonizado, miticamente representado como o indivíduo mau, inferior, indolente e preguiçoso. Como explica Memmi (1977: 21):

Muitos ainda imaginam o colonizador como um homem de grande estatura, bronzeado pelo sol, calçado com meias-botas, apoiado em uma pá - pois não deixa de pôr mãos à obra, fixando seu olhar ao longe, no horizonte de suas terras; nos intervalos de sua luta contra a natureza, dedicando-se aos homens, cuida dos doentes e difunde a cultura, um nobre aventureiro, enfim, um pioneiro.

Trata-se da visão mística, justificadora do processo colonial. O colonizador como o homem de bem, civilizado, que ajuda a salvar os miseráveis bárbaros da periferia do mundo. Mas, como aponta Memmi (1977), o colonizador é antes de tudo o usurpador ilegítimo. Por outro lado, “[...] a situação colonial fabrica colonialistas, como fabrica colonizados." (MEMMI, 1977: 59).

E sobre isso acrescenta Memmi (1977: 68) que "Não é uma coincidência: o racismo resume e simboliza a relação fundamental que une colonialista e colonizado". O autor (1977) sustenta que o racismo é a característica por excelência do colonialismo e que a figura do colonizadoré sempre auto-absolvida pela mística salvadora da civilização contra a barbárie do colonizado

Destaca Memmi a ideia central do colonizador sobre o colonizado como ser infame e preguiçoso. Como assinala o autor (1977: 78): “Ao ouvi-lo, aliás, descobre-se que o colonizador não está tão aborrecido assim com essa preguiça,suposta ou real. Faladela com uma complacência bem-humorada, diverte-se com ela; retoma todas 
as expressões habituais e as aperfeiçoa, e com elas inventa outras. Nada é suficiente para caracterizar a extraordinária deficiência do colonizado".

O sarcasmo é tão exacerbado que a tal debilidade do colonizado é reclamada pelo colonizador como motivo de proteção ao colonizado (MEMMI, 1977). Nesse sentido, enfim, o retrato do colonizado é indicado por Memmi (1977: 82):

Enfim o colonizador nega ao colonizado o direito mais precioso reconhecido à maioria dos homens: a liberdade. As condições de vida, dadas ao colonizado pela colonização, não a levam em conta, nem mesmo a supõem. O colonizado não dispõe de saída alguma para deixar seu estado de infelicidade: nem jurídica (a naturalização) nem mística (a conversão religiosa): o colonizado não é livre de escolher-se colonizado ou não colonizado.

O colonizado é o ser negativado (MEMMI, 1977) ou, como relata Fanon (1968: 32), "No contexto colonial, o colono só dá findo seu trabalho de desancamento do colonizado quando este último reconhece em voz alta e inteligível a supremacia dos valores brancos". Esse é o primeiro momento da crítica anticolonial nascida na própria periferia. Porém, não como teórico, mas como líder político e espiritual, Mahatma Gandhi, no processo da independência da Índia do julgo britânico, deu início à luta da descolonização e ao rompimento da opressão tipicamente colonial.

\section{Pós-colonialismo}

Posteriormente, na década de 1970 e de 1980, despontaram teorias desdobradas do anticolonialismo, conhecidas como pós-colonialismo e decolonialismo. Pelo nome de teorias pós-coloniais, se entende primeiramente as análises elaboradas a partir de ex-colônias do Império Britânico, notadamente Índia e Oriente Médio. Como aponta Chamecki (2010: 121): “A crítica pós-colonial, ou pós-colonialismo, tem como eixo fundante a proposta de desvelar os efeitos do colonialismo nosmais diversos setores das sociedades colonizadas, em especial políticos, filósofos culturais e artísticos, e mesmo suas influências na formação das sociedades colonizadoras".

Trata-se de um novo período crítico, não mais com o conceito fechado de colonialismo da teoria anticolonial. A ideia de colonialismo não se limita ao período histórico que compreende as fases da ocupação colonial até o descolonialismo pósguerra. Nesse sentido, Chamecki (2010: 121) acrescenta que "O "pós" como prefixo do 
termo colonialismo não se limita a descrever período ou condição posterior à suposta superação dos laços coloniais. Indica releitura da narrativa histórica sob outro viés [...]”. Passa a analisar a herança presente do colonialismo nas sociedades colonizadas.

Nessa fase pós-colonial, destacam-se o crítico literário palestino Edward Said e os indianos Homi Bhabha - analisando o colonizado como um tipo construído degenerado, com base em estereótipos e hibridismos - e Gayatri Spivak - que, por intermédio da teoria literária marxista, feminista e mesmo psicanalítica, denuncia o discurso colonizador sobre o colonizado.

Complementa Chamecki (2010: 122) que:

É usual a menção à repercussão alcançada pelo crítico literário palestino Edward Said com a publicação da obra "Orientalismo" (1978), em que alertava que a distorcida visão ocidental do Oriente como o "Outro" servia aos interesses coloniais. Uma primeira vertente pós-colonialistaque adquiriu relativa homogeneidade em suas proposições foi formada por Said e outros estudiosos asiáticos radicados nos Estados Unidos, com destaque para Homi Bhabha e Gayatri Chakravorty Spivak. Tinha como eixo temático fundante a analise crítica da historiografia colonial e eurocêntrica.

Nesse sentido,Edward Said (1978) apresenta uma contribuição considerável em sua obra "Orientalismo", na qual defende a tese de que a ideia sobre o oriental não passa de um discurso construído pelo imaginário colonialista.

$\mathrm{Na}$ análise do autor, o anti-islamismo assume uma figura de destaque. Como aponta Said (1990: 38):

A vida de um árabe palestino no ocidente, especialmente nos Estados Unidos, é desanimadora. Existe aqui um consenso quase unânime de que politicamente ele não existe e, quando admitido que ele existe, é como um incomodo ou como um oriental. A teia do racismo, dos estereótipos culturais, do imperialismo político e da ideologia desumanizante que contém o árabe ou o muçulmano é realmente muito forte, e é esta teia que cada palestino veio a sentir como seu destino singularmente punitivo.

Apesar de discursos políticos moderados, a questão islâmica está no centro do debate do terrorismo internacional, e uma verdadeira campanha anti-islã é promovida no cenário político. A imagem caricata do muçulmano barbudo e irracional prestes a 
explodir uma bomba, até a vontade de generalizar a democracia liberal para o mundo islâmico, esconde por detrás uma etiquetagem de barbárie. Esso processo se explica por várias razões. Como aduz Said (1990: 38):

Três coisas contribuíram para transformar até mesmo a mais simples percepção dos árabes e do islã, em uma questão altamente politizada, quase áspera: uma, a história do preconceito popular anti-árabe e anti-islâmico no Ocidente, imediatamente refletido na história do orientalismo; duas, a luta entreos árabes e o sionismo israelita, e os seus efeitos sobre o judeu americano, bem como sobre a cultura liberal e a população em geral; três, a quase total ausência de qualquer posição cultural que tornasse possível, seja identificar-se com os árabes e com o islã, seja discuti-los com isenção. Além disso, quase não é preciso dizer que, posto que o Oriente Médio está hoje identificado com a política das Grandes Potências, com a política do petróleo, e com a dicotomia simplista do democrático e amante da liberdade Israel e os árabes maus, totalitários e terroristas, as chances de qualquer coisa parecida com uma visão clara de sobre o que se está falando quando se está falando sobre o Oriente próximo são depressivamente pequenas.

E a imagem do islã terrorista é difundida também no meio acadêmico, como sustentado por Huntington (1997: 68) em seu conhecido trabalho sobre o "Choque das Civilizações": "Em algum ponto do oriente médio, uma meia dúzia de rapazes bem poderia estar vestindo calçasjeans, bebendo coca-cola, escutando rap e, entre suas reverências na direção de Meca, estar montando uma bomba para explodir um avião comercial norte-americano". Essa visão do Outro como inimigo é a imagem da barbárie, da humanidade não reconhecida, desprezada, negada. O estereótipo do muçulmano é do irracional, anti-humano, não civilizado, ameaçador dos valores cristãos, europeus, liberais e democráticos. O conjunto dessas características forma o quadro do bárbaro, presente na representação social do islâmico, bem apontado por Said (1990: 117):

Os árabes, porexemplo, são vistos como libertinos montados em camelos, terroristas, narigudos e venais cuja riqueza não merecida é uma afronta à verdadeira civilização. Há sempre nisso a presunção de que o consumidor ocidental, embora pertença a uma minoria numérica, tem direito 
a possuir ou a gastar (ou ambas as coisas) a maioria dos recursos mundiais. Por quê? Porque ele, ao contrário do oriental, é um verdadeiro ser humano.

A proposição é clara: uma parte da população mundial, importante, a menor parte, é ocidental e, do outro lado, estão os orientais - árabes. Os primeiros, como acrescenta Said (1990: 59) são "racionais, pacíficos, liberais, lógicos, capazes de ter valores reais, sem desconfiança natural; os últimos não são nada disso"; ou seja, uns são humanos e outros descartados desse reconhecimento. Reproduz-se o processo histórico da barbárie, da exclusão e do etnocentrismo.

Duas ideias equivocadas são difundidas:a primeira que o fundamentalismo islâmico faz parte permanentemente e exclusiva da história do Oriente Próximo e a segunda que o terrorismo é produto político genuinamente islâmico. Na verdade, o fundamentalismo islâmico, ao contrário, é um fenômeno relativamente recente (HALLIDAY, 1999), e o terrorismo tem como principal registro histórico a Revolução Francesa, marco fundamental da tradição ocidental, mais em específico o regime político de setembro de 1793 a julho de 1794. O terrorismo foi amplamente utilizado pelo movimento anarquista na Europa; e o fundamentalismo tem um sentido muito mais amplo do que o Islamismo. Como observa Halliday (1999: 94), "Apesar de toda ênfase sobre o mundo islâmico, o termo fundamentalismo aplica-se muito mais amplamente. Ele engloba a tendência já mencionada na cristandade das facções protestantes evangélicas que emergiram nos 1920 e pediam um retorno a uma leitura literal da Bíblia".

De forma mais enfática, Halliday acrescenta (1999: 297):

Todos estes movimentos fazem muito barulho sobre a agressividade e as conspirações de seus inimigos e como eles próprios são vítimas. Mas frequentemente existe uma forte dose de projeção em tudo isso. No momento, o mundo ocidental, cristão e pós-cristão, está dizendo muito sobre quão agressivo o Islã é e como ele ameaça o ocidente: mas o estudo mais elementar da história do mundo ao longo dos últimos três séculos sugeriria que a bota, pelo contrário, está no outro pé, permanecendo assim em muitas partes do mundo. Na Bósnia, foram os antimuçulmanos, os sérvios ortodoxos e os católicos croatas, que mais fizeram para envenenar as relações intercomunais. 
É importante considerar também que tanto o cristianismo judaico como o islamismo possuem matrizes religiosas irmãs. Ambas as religiões têm em comum fundamentos essenciais: a centralidade monoteísta; o perfil missionário de alcançar os não convertidos; a noção salvacionista generalizada; a pretensão de validade universal. Esse conjunto de fatores resultam em ideologias, não democráticas, nem pluralistas, capazes de permitir movimentos extremados de perseguição e segregação (HUNTINGTON, 1997). Ou seja, são fundamentalistas, radicais, promotoras de perseguições étnicas e religiosas, podendo-se falar em terrorismo religioso.

Nesse sentido, sabe-se o quanto o cristianismo produziu de cruzadas e tribunais, e que ainda, em muitos setores e grupos cristãos, o fundamentalismo baseado na leitura literal dos textos sagrados se fortalece, impondo uma visão extremamente intolerante. $\mathrm{O}$ etnocentrismo contra o Islã é sintetizado por Huntington (1997: 273) nesses termos:

O problema subjacente para o ocidente não é o fundamentalismo islâmico. É o Islã, uma civilização diferente, cujas pessoas estão convencidas da superioridade de sua cultura e obcecadas com a inferioridade de seu poderio." Percebe-se que não se trata do apelo ao fundamentalismo e ao terrorismo, mas ao Islamismo e ao árabe em si, por não corresponder as matrizes civilizacionais ocidentais. O problema está na diferença, na diversidade cultural, difícil de ser compreendida e respeitada.

O problema relacionado aoislamismo é o problema do etnocentrismo eurocêntrico, presente durante todo processo histórico do colonialismo e da colonialidade.

\section{Descolonialismo e colonialidade}

Como já mencionado anteriormente, para os autores descolonialistas, colonialismo e colonialidade são categorias próximas, mas não idênticas; ou seja, se o colonialismo compreende um período histórico de opressão, indo ao se processar a independência física das ex-colônias, colonialidade se reporta a uma dominação mais profunda e abrangente, tanto de poder quanto do ser e do saber. As teorias descoloniais partem do binômio modernidade-colonialidade, investigando a herança presente do colonialismo histórico. Ressalta-se que a ideia da colonialidade se estende inclusive no campo simbólico das representações sociais do imaginário colonial. 
Os autores da descolonialidade trabalham com base em outro paradigma epistemológico, vindo do sul, e não da crítica eurocêntrica ao eurocentrismo. Conhecidos como teóricos do "Grupo Modernidade-Colonialidade," filósofo argentino Enrique Dussel, o sociólogo peruano Anibal Quijano, o semiólogo e teórico cultural argentino-norte-americano Walter Mignolo, o sociólogo porto-riquenho Ramón Grosfoguel, a linguista norte-americana radicada no Equador Catherine Walsh, o filósofo porto-riquenho Nelson Maldonado Torres, o antropólogo colombiano Arturo Ecobar, entre outros.

Nesse sentido, Grosfoguel (2008) afirma que essa corrente teórica teve como momento importante o Congresso realizado na Universidade de Duke em 1998, quando a vertente do pensamento pós-colonial formada por autores latino-americanos deu origem à formação do "Grupo Latino-americano de Modernidade-Colonialidade". Tratou-se de buscar uma própria epistemelatino-americano, diferentemente dos autores pós-coloniais, transcendendo, assim, os limites do colonialismo. Essa opção teórica relacionada aos estudos sobre o descolonialismo passou a ser entendida como "Giro descolonial", buscando uma libertação do eurocentrismo, no plano dos saberes, dos seres e do poder. Como descreve Chamecki (2010: 123):

Esse "giro descolonial"foi capitaneado por Warter Mignolo, com destaque, dentre outros, para o pensamento de Enrique Dussel, Anibal Quijano, Nelson Maldonado-Torres, Ramon Grosfoguel, Arturo Escobar, Santiago Castro-Gomes e Catherine Walsh. Carateriza-se por sustentar que a crítica ao eurocentrismo moderno deve ser construída "de baixo", do horizonte dos povos localizados no lado obscuro da modernidade, do contexto cultural e social daqueles que foram inferiorizados e vilipendiados pela normatização moderna, da experiência histórica das vítimas da faceta violenta da modernidade.

Posteriormente, em julho de 2002, Arturo Escobar, antropólogo colombiano e professor da Universidade da Carolina do Norte, no terceiro Congresso Internacional de Latino-americanistas, em Amsterdã, apresentou a síntese do grupo de pesquisa "Modernidade-Colonialidade", inserido nos estudos subalternos. Na ocasião,Escobar analisava a perspectiva de uma nova epistemologia, alternativa à modernidade eurocêntrica, como aponta Mignolo (2005: 75), “[...] a colonialidade é constitutiva da

\footnotetext{
${ }^{1}$ Anibal Quijano considerado fundador do termo.
} 
modernidade, e não derivada [...]”, ou seja, em virtude da colonialidade, a Europa conseguiu propor as ciências humanas como modelo único, universal, descartando todos os saberes da periferia do Ocidente.

Como explica Mignolo (2006: 124), o pensamento descolonial é diferente dos movimentos críticos eurocêntricos - como, por exemplo, o pós-colonialismo ou o pósmodernismo, ou o pós-estruturalismo - pois essas perspectivas não rompem com a relação imperialista. São "críticas eurocêntricas ao eurocentrismo europeu”.

Nessa direção, Mignolo (2006) afirma que a lógica colonial atua em três campos diversos: a colonialidade do poder, implicitamente com seu viés político e econômico; a colonialidade do saber, como discurso epistemologicamente único e verdadeiro, tanto na filosofia como na ciência; a colonialidade do ser, fundamentalmente inserido na sexualidade do colonizado e em outros elementos.

Esses três níveis do controle colonial, constitutivo da colonialidade /modernidade, tornam o colonizado um não ser, pois, além de ser destituído do reconhecimento do seu saber, torna-o duplamente cativo,do colonizador e de si mesmo, pois a colonialidade opera não apenas de fora para dentro, mas de dentro do próprio colonizado. Esse é otema central da proposta descolonialista da colonialidade. Como assevera Chamecki (2010: 127), “O pensamento descolonial tem como objeto a análise da colonialidade como face constitutiva e oculta da modernidade, e como projeto descolonizar o saber, o poder e o ser".

Observa Mignolo (2006: 12) que:

El pensamento descolonial [...] se hace pensando se em variadas formas semióticas, paralelas y complementarias, a movimientos sociales que se mueven em los bordes e y em los márgenes de las estructuras políticas (estado, partidos políticos) y económicas (explotacion, acumulacion, opresion), pensandose em desprendimiento de La imagen de uma totalidad que, com el mundo de "the Truman Show", nos hace creer que no hay literalmente, salida. El desprendimiento que promueve el pensamento descolonial con lleva La conianza em que otros mundos son posibles (no uno nuevo y único que creamos será "mejor", sino otros-diversos) y que estanya en proceso de construccion, planetariamente.

Trata-se darazão subalterna, não que as críticas eurocêntricas sobre o eurocentrismo ocidental sejam inválidas ou desmerecedoras de diálogo e reflexão 
teórica, mas limitadas ao imaginário epistemológico fundamentado na colonialidademodernidade, ou seja, uma consciência com base nas categorias civilização e barbárie, ou Modernidade. Como descreve Mignolo (2003: 139-140):

Sugiro que a razão subalterna seja entendida como um conjunto diverso de práticas teóricasemergindo como um conjunto diverso dos e respondendo aos legados coloniais na interseção da história euroamericana moderna. Não chego ao ponto de comentar ou encarar o póscolonial como um novo paradigma, mas vejo-o como parte de um outro maior, precisamente o que caracterizo como gnose liminar, um outro pensamento a partir e para além das disciplinas e da geopolítica do conhecimento, embutidas nos estudos de área; a partir e para além dos legados coloniais; a partir e para além das divisões de gênero e prescrições sexuais; e a partir e para além dos conflitos raciais. Assim, a gnose liminar é um anseio de ultrapassar a subalternidade e um elemento para a construção de formas subalternas de pensar.

Esse pensamento liminar, categoria irmã da razão subalterna, significa a descentralização dageopolítica do saber. Eisso compreende o rompimento do binômio civilização/barbárie, modernidade/colonialidade.

O resultado dessa epistemologia histórica da modernidade/colonialidade é a exclusão radical, a degeneração do Outro, a barbarização do Outro, na negatividade totalizante do colonizado. Como orienta Ludwing (2004: 195):

Ooutro enquanto exterioridade irrompe racionalmente como de uma espécie de nada (sem as determinações semânticas da lógica da totalidade dominante) - do infinito como quer Lévinas. O princípio básico é o da libertação da exclusão; libertação da miséria e da opressão de todas as lógicas de dominação no plano concreto: este é o fundamento - razão do outro enquanto exterioridade. Desta forma, a racionalidade é a condição da libertação, na modalidade da racionalidade excluída. Não existe, por outro lado, racionalidade crítica sem sua fonte epistemática e eticamente originária: a dimensão da exterioridade.

No mesmo sentido, aponta Chamecki (2010: 128) que "A lógica colonial que subjaz a retórica da modernidade resulta em uma massa de seres humanos humilhados, 
marginalizados, esquecidos e vilipendiados". Barbárie e colonialidade podem ser interpretadas como duas faces da mesma moeda. Todo o processo da Modernidade dividida entre civilização e barbárie trata-se da dicotomia entre modernidadecolonialidade. Essa observação está inserida dentro de uma perspectiva de mundialidade sistêmica, categoria chamada por Mignolo de sistema-mundo. O resultado desse processo chama-se eurocentrismo. Para Quijano (1993: 221-222):

\begin{abstract}
Algunos de los elementos más importantes Del eurocentrismo: a) uma articulación peculiar entre um dualismo (precapital-capital, no europeoeuropeo, primitivo-civilizado, tradicional-moderno, etc.) y um evolucionismo lineal, unidirecional, desde algún estado de naturaleza a La sociedad moderna europea; b) la naturalizacion de las diferencias culturales entre grupos humanos por médio de su codiicación com La Idea de raza; y c) La distirsiona da reubicacion temporal de todas esas diferencias, de modo que todo lo no-europeo es percibido como pasado. Todas estas operacion es intelectuales son claramente interdependendientes. Y no habrian podido ser cultivadas y desarrolla das sin La colonialidad Del poder.
\end{abstract}

O eurocentrismo marcado pelo dualismo é em síntese o problema entre a civilização e barbárie. Entreos sujeitos e as coisas, um processo de coisificação pensado e repensado pela categoria modernidade-colonialidade. O Outro é manifestado pela negatividade, pela não existência. Para o rompimentodessa lógica, torna-se necessária a razão subalterna, ou alterativa.

Como indica Chamecki (2010: 131):

[...] a figura central dessa compreensão da realidade que se traduz numa forma diversa de razão é a abertura para o Outro, isto é, para reconhecimento de sua dignidade e autonomia a partir de lógica que transcenda os limites da totalidade do sistema moderno baseado na eurocêntrica visão da modernidade, adota-se sua caracterização de "razão alterativa".

A subalternidade está justamentena abertura para a alteridade. Implicadiretamente na desconstituição das bases eurocêntricas do poder, do saber e do ser moderno, pois o eurocentrismo “[...] torna-se, portanto, uma metáfora para descrever a colonialidade do poder, na perspectiva da subalternidade [...]" (MIGNOLO, 2003: 41). 
E, mais adiante, complementa Mignolo sobre a epistemologia da modernidade: “[...] o saber e as histórias locais europeias foram vistos como projetos globais [...] até a crença de Hegel em uma história universal, narrada de uma perspectiva que situa a Europa como ponto de referência e de chegada".

O eurocentrismo é uma derivação do etnocentrismo, ou seja, a visão do Outro como diminuída, negada, inferiorizada. Em outras palavras, trata-se de tomar narcisamente sua própria imagem como referência absoluta daquilo que se pensa sobre o que é o humano. Nesse processo, surgem os estigmas, as segregações, os genocídios e toda manifestação da colonialidade, do poder, do saber e do ser.

Dessa forma, percebe-se uma profunda aproximação teórica entre a Filosofia da Libertação de Enrique Dussel e a modernidade-colonialidade defendida por Walter Mignolo e demais autores descolonialistas do Grupo Latino-americano de estudos subalternos. Não é objetivodesta pesquisa esmiuçar as inevitáveis diferenças de ordem teórica, mas perceber os pontos significativamente próximos das duas propostas descolonialistas. Como pensa Chamecki (2010: 135) "A conexão entre a filosofia da libertação em Dussel e o pensamento descolonial é muito estreita. O próprio Mignolo faz inúmeras remissões e aproveita diversos conceitos e categorias extraídas da teoria da libertação [...]”. E depois ainda complementa “[...] é possível afirmara existência de eixo comum entre filosofia da libertação e pensamento descolonial" (CHAMECKI, 2010: 130).

Percebe-se em ambos os discursos descolonialistas a fundamentação da razão alterativa, a abertura para o Outro e o rompimento epistemológico do conhecimento eurocêntrico.

Concorda-se com Chamecki (2010: 138), no sentido de que "[...] a despeito da utilização de categorias e nomenclatura diversas, as premissas subjacentes a razão pósocidental ou subalterna da perspectiva descolonial são muito próximas da razão do Outro da teoria da libertação".

A Filosofia da Libertação, como a modernidade/colonialidade são discursos descolonialistas, no sentido de libertação, emancipação do colonizado, tanto no aspecto do ser quanto no do poder e do saber. 


\section{Referências bibliográficas}

CHAMECKI, Eduardo (2010). Dahermenêutica filosófica à hermenêutica críticoalterativa: caminhos para a descolonização do saber jurídico. Curitiba: Universidade Federal do Paraná.

FANON, Frantz (1968). Os condenados da terra. Rio de Janeiro: Civilização brasileira.

GROSFOGUEL, Ramon (2008). Para descolonizar os estudos de economia Política e os estudos pós-coloniais: transmodernidade, pensamento de fronteira e colonialidade global. Revista Crítica de Ciências Sociais, Coimbra, n. 80: 115-119.

HALLIDAY, Fred (1999). Repensando as relações internacionais. Porto Alegre: UFRGS.

HUNTINGTON, Samuel P. (1997). O choque de civilizações e a recomposição da ordem mundial. Rio de Janeiro: Objetiva.

LUDWIG, Celso Luiz (2004). Da ética à filosofia política crítica na transmodernidade: reflexões desde a filosofia de Enrique Dussel. In: FONSECA, Ricardo Marcelo (Org.). Repensando a teoria do Estado. Belo Horizonte: Forum: 286-287.

MALDONADO-TORRES, Nelson (2007). Sobre La colonialidad Del ser: contribucionesaldesarrollo de um concepto. In:CASTRO-GOMEZ, S.; GROSFOGUEL, R. (Org.). El giro decolonial Relexiones para uma diversidad epistêmica más Allá Del capitalismo global. Bogotá: UniversidadJaveriana-Instituto Pensar, Universidad Central-IESCO, Siglo Del Hombre editores.

MIGNOLO, Walter (2005). A colonialidade de cabo a rabo: o hemisfério ocidental no horizonte conceitual da modernidade. IN: LANDER, E. (Org.). A colonialidade do saber: eurocentrismo e ciências sociais. Perspectivas latino-americanas. Buenos Aires: Clacso.

MIGNOLO, Walter D. (2003). Histórias locais/projetos globais: colonialidade, saberes subalternos e pensamento liminar. Belo Horizonte: UFMG.

MIGNOLO, Walter (2006). El desprendimiento: pensamiento crítico y giro descolonial. In: SCHIWY, Freya; MADONADO-TORRES, Nelson; MIGNOLO, Walter D. Des-colonialidad del ser y del saber. Buenos Aires: Del Signo: 21-22.

MEMMI, Albert (1977). O retrato do colonizado precedido pelo retrato do colonizador. Rio de Janeiro: Paz e Terra.

QUIJANO, Anibal (2007). Colonialidad Del poder y clasificación social. In:CASTRO-GOMEZ, S.; GROSFOGUEL, R. (Org.). El giro decolonial. Reflexiones para uma diversidad epistémica más Allá Del capitalismo global. Bogotá: Universidad Javeriana-Instituto Pensar, Universidad Central-IESCO, Siglo Del Hombre editores.

QUIJANO, Anibal (1993). Colonialidade Del poder, eurocentrismo y América Latina. IN:LANDER, Edgardo (Org.). La colonialidad del saber: eurocentrismo y ciencias sociales. Perspectivas latinoamericanas. Buenos Aires: Clacso.

SAID, Edward (1990). Orientalismo: oriente como invenção do ocidente. São Paulo: Companhia das letras.

Artigo recebido em 29 de setembro de 2020.

Aprovado em 21 de maio de 2021.

DOI: 10.12957/intellectus.2021.59840 